Ophthalmologica

\title{
Minimally Invasive Strabismus Surgery for Rectus Muscle Posterior Fixation
}

\author{
Daniel S. Mojon \\ Department of Strabismology and Neuro-Ophthalmology, Kantonsspital, St. Gallen, and University of Bern, \\ Bern, Switzerland
}

\section{Key Words}

Strabismus surgery $\cdot$ Minimally invasive surgery $\cdot$ Minimally invasive strabismus surgery $\cdot$ Conjunctival opening •

Rectus muscle posterior fixation

\begin{abstract}
Aims: To present a novel, minimally invasive strabismus surgery (MISS) technique for rectus muscle posterior fixation. Methods: This study reports the results of 32 consecutive MISS rectus muscle posterior fixation surgeries performed on 19 patients by applying only two small L-shaped openings where the two retroequatorial scleromuscular sutures were placed. Results: On the first postoperative day, in primary position, redness was hardly visible in 16 eyes (50\%) and only moderate redness was visible in 6 eyes (19\%). No serious complication occurred. Preoperative visual acuity and refraction remained unchanged at 6 months $(p>0.1)$. The preoperative convergence excess $(n=13)$ decreased from $10.3 \pm 4.1$ to $5.2 \pm 4.0^{\circ}$ at 6 months $(p<0.005)$. In all patients operated on for gaze incomitance $(n=6)$ improvement was achieved at 6 months. Conclusions: This study shows that keyhole minimal-dissection rectus muscle posterior fixation surgery is feasible and effective to improve ocular alignment. The MISS technique seems to be superior in the direct postoperative period since only minimal conjunctival swelling and no corneal complications were observed.
\end{abstract}

Copyright $\odot 2008$ S. Karger AG, Basel

\section{Introduction}

Minimally invasive surgical techniques aim at reducing tissue traumatism, postoperative patient discomfort, hospital stay, working disability and the economic impact of surgery $[1,2]$. Keyhole openings have replaced larger cuts in many surgical fields [1]. Eye surgeons also have developed several keyhole or otherwise minimally invasive procedures for lids [3], the lacrimal system [4], conjunctiva [5], cataracts [6], glaucoma [7] and vitreoretinal surgery [8].

In strabismus, several surgical techniques have been proposed to reduce the conjunctival incision size since it is one of the major components influencing the postoperative quality of life, cosmesis, the function of the operated muscle, and the ease to perform reoperations. For rectus muscle surgery, many surgeons use the limbal approach first described by Harms [9] in 1949 and later popularized by von Noorden [10]. Parks' opening technique, a fornix incision for the conjunctiva and Tenon's capsule, is also widely used in patients with elastic conjunctiva [11]. Several other, more rarely used modifications of the conjunctival opening have been published [12-14]. In 2007, I described a novel minimally invasive strabismus

The president of the Ethical Committee of the Canton of St. Gallen approved the use of this new surgical technique.

\section{KARGER}

Fax +41613061234 E-Mail karger@karger.ch www.karger.com
Prof. Dr. med. Daniel Mojon

Department of Strabismology and Neuro-Ophthalmology

Kantonsspital

CH-9007 St. Gallen (Switzerland)

Tel. +41 7149428 24, Fax +41 7149428 82, E-Mail daniel.mojon@kssg.ch 
Fig. 1. Schematic representation of Harms' conjunctival opening and the new transposition MISS technique for rectus muscle posterior fixation. The eye is represented from above as seen by the surgeon. So far, rectus muscle posterior fixation sutures have been performed using the large Harms' limbal opening (a, b). With the new MISS technique, after applying a limbal traction suture, two small L-shaped cuts are performed slightly anterior to the site where the scleromuscular sutures will be placed (c). The episcleral tissue is separated from the muscle sheath and the sclera with blunt Wescott scissors. Then, a curved ruler is used to determine the exact placement of the scleromuscular sutures (d). The posterior fixation is performed by first passing a nonresorbable suture through the sclera (e), followed by the muscle suture, which will include one third of the muscle (f). g Final appearance of the scleromuscular suture. Then, using the same technique, a posterior fixation suture is placed at the other border of the muscle (h). The surgical procedure is completed by applying resorbable single sutures to the two small cuts (i). For better visualization of the operating site, the cuts can be enlarged or joined at the limbus in order to obtain the usual limbus approach (a).
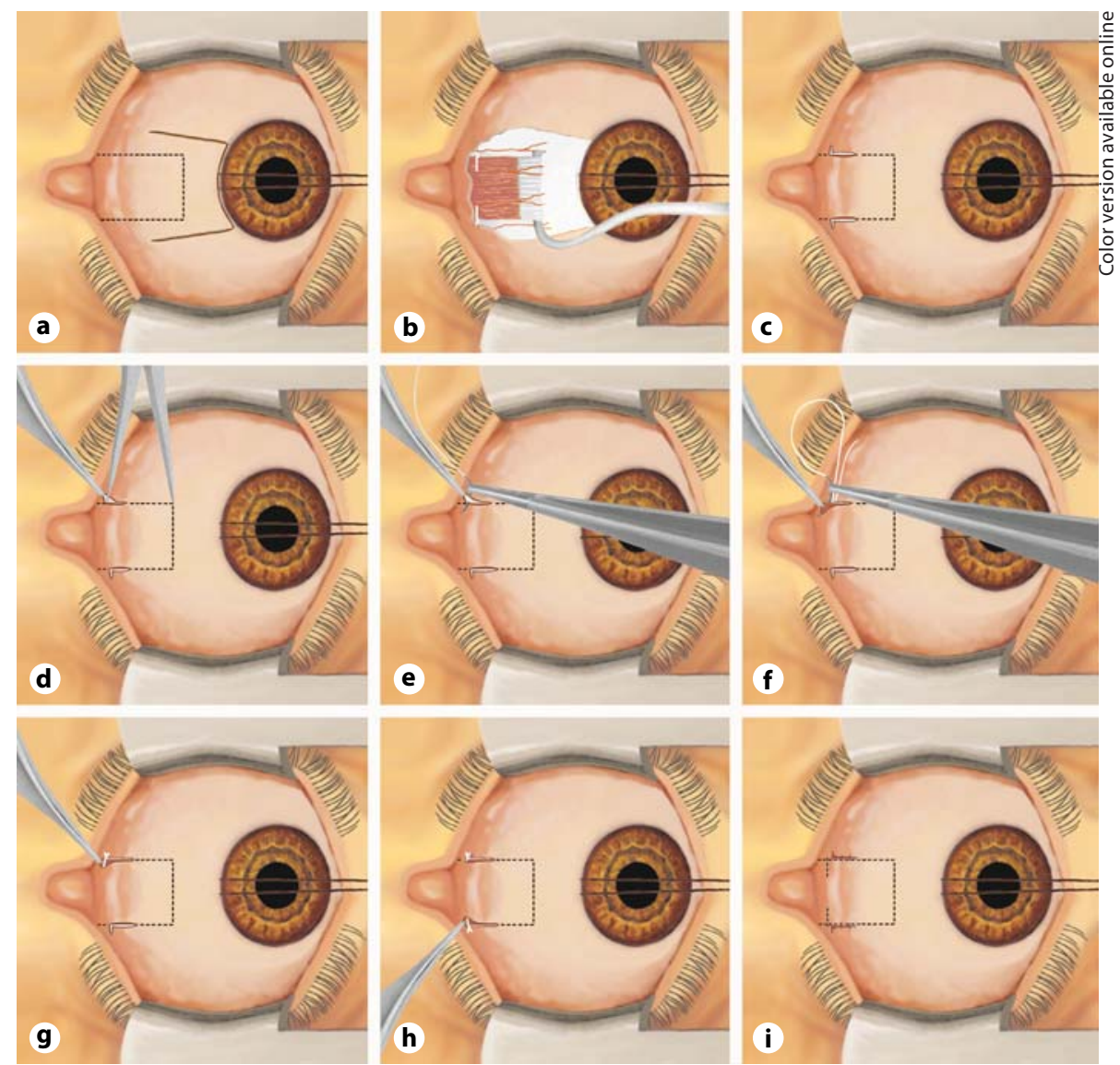

surgery (MISS) technique using keyhole cuts for rectus muscle recessions and plications and compared it to Harms' limbal opening [15]. Surgery is performed by applying two small radial cuts along the muscle insertion. After muscle separation from surrounding tissue, a recession or a plication is performed through the resulting tunnel. MISS patients had better visual acuities and less lid swelling the day after surgery compared to those operated on with the normal limbal approach, indicating that this minimal dissecting procedure is superior in the direct postoperative period. MISS also allows to perform rectus muscle repeat surgery [16] and graded inferior oblique muscle recessions [17].

In this study, the principle of keyhole surgery was used to perform rectus muscle posterior scleromuscular fixations. Posterior anchoring of a rectus muscle is indicated for incomitant strabismus to reduce the force in the agonist contralateral to the weak muscle, to correct near/distance incomitance, reduce dissociated vertical deviation, or decrease the amplitude of nystagmus. So far, rectus muscle posterior fixation surgery was only performed through Harms' large limbal openings (fig. la, b). This often induces considerable conjunctival and lid swelling during the immediate postoperative period and may even lead to corneal surface problems. MISS for rectus muscle posterior fixation is performed by applying two small Lshaped openings where the two retroequatorial scleromuscular sutures are placed. This access and tissue dissection technique should only induce minimal anatomical disruption and will ensure that postoperatively all openings remain covered by the eyelids.

\section{Patients and Methods}

This study presents the results of the first 32 consecutive eyes from 19 patients operated on with the MISS rectus muscle posterior fixation technique at the Kantonsspital of St. Gallen. The investigation followed the tenets of the Declaration of Helsinki. The president of the Ethical Committee of the Canton of St. Gallen approved the use of this new technique. 


\section{Patients}

Patients Undergoing Posterior Anchoring with the MISS

Technique

Inclusion criteria: All consecutive patients needing rectus muscle posterior fixation surgery operated on by the author between March 2003 and July 2007 were included. No patient was excluded during this time period. All patients had at least one complete orthoptic examination 5 days before the surgical procedure, on the first postoperative day and after 6 months (range 5-7 months) at the Department of Strabismology and NeuroOphthalmology, Kantonsspital, St. Gallen, Switzerland. Between day 1 and 6 months, only patients with complications or not referred by an ophthalmologist were seen at our department. The referring ophthalmologists followed the other patients. The schedule of follow-up visits in-between was at day 10 (range 1-2 weeks) and week 4 (range 3-5 weeks).

The following parameters were registered: deviation, head posture, field of binocular single vision, motility, stereovision, visual acuity, refraction, lid and conjunctival swelling and redness, and number and types of complications. All prism cover test measurements were recorded while the patient's nonparetic eye was fixating. Voluntary ductions estimated with a 6-point scale from 0 to -5 : 0 = eye has full movement, $-4=$ eye is unable to move past the midline, and $-5=$ eye cannot be moved to the midline [18]. Binocular single vision was measured using Bagolini's striated glasses and the Harms tangent screen [19].

\section{Surgical Method}

Surgical Technique for MISS Rectus Muscle Posterior

Fixation

The surgical procedure is performed using the operating microscope under general anesthesia. All surgical steps can be performed by the surgeon without an assistant. A limbal traction suture (SilkamS 6-0; B. Braun Medical AG, Sempach, Switzerland) is applied in order to expose the rectus muscles, which have to be weakened. During surgery, direct contact of the traction suture with the cornea has to be avoided. Next, two small L-shaped cuts are performed slightly anterior to location where the scleromuscular sutures will be placed (fig. 1c). The size of the radial cut is $4 \mathrm{~mm}$, the relaxing cut $2 \mathrm{~mm}$. In patients with reduced elasticity of the conjunctival tissue, slightly larger openings will be necessary. In 9 eyes, the cuts were prolonged by approximately $3 \mathrm{~mm}$ more anteriorly in order to enable an additional minimal invasive recession or plication. The episcleral tissue is separated from the muscle sheath and the sclera with blunt Wescott scissors. Then, a curved ruler is used to determine the exact placement of the scleromuscular sutures (fig. 1d). The posterior fixation is performed by first passing a nonresorbable suture through the sclera (fig. 1e), followed by the muscle suture, which will include one third of the muscle (fig. 1f). In this patient series, a PreMicron ${ }^{\circledR}$ 5-0 (B. Braun Medial AG) suture was used. The suture is tightened by a three-throw adaptation suture followed by two securing loops (fig. 1g). Then, using the same technique, a posterior fixation suture is placed at the other border of the muscle (fig. 1h). If necessary, hemostasis is performed. The surgical procedure is completed by applying single sutures $\left(\mathrm{Vicryl}^{\circledR}\right.$ Rapid 8-0; Ethicon, Spreitenbach, Switzerland) to the two small cuts (fig. 1i). At the end of the operation, TobraDex ${ }^{\circledR}$ ointment ( $1 \mathrm{mg}$ dexamethasone and $3 \mathrm{mg}$ tobramycin per gram, $0.5 \%$ chlorobutanol) or Maxitrol ${ }^{\circledR}$ ointment (polymyxin B sulfate, 6,000 units, neomycin sulfate,
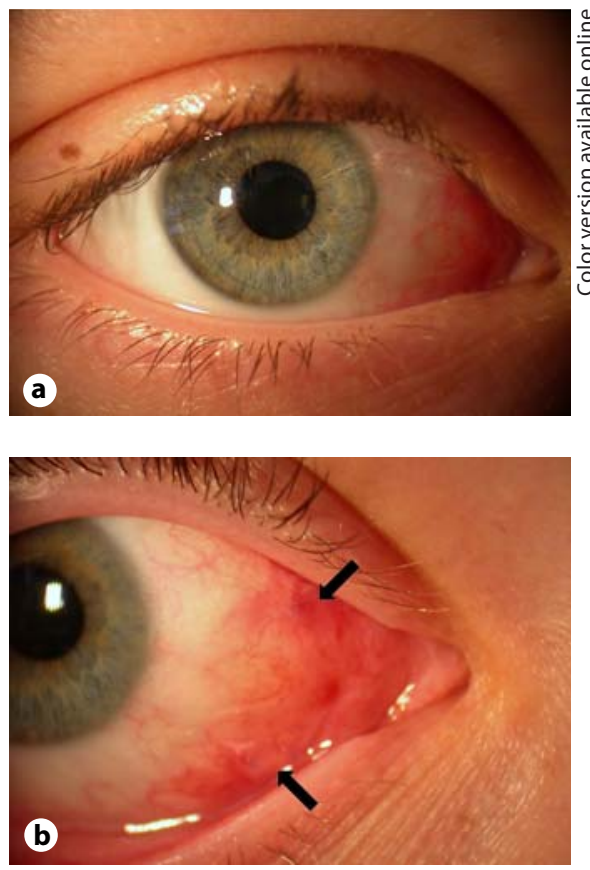

Fig. 2. Photographs of a 16-year-old patient necessitating medial rectus posterior fixation surgery because of convergence excess taken $24 \mathrm{~h}$ after surgery. The eye could be opened very well and there was only minimal discomfort. In primary position, the cuts were covered by the lids, and the perilimbal conjunctiva showed only minimal redness (a). The keyhole openings become visible on right gaze (b, black arrows).

3,500 units, dexamethasone $1.0 \mathrm{mg}$, methylparaben $0.05 \%$, and propylparaben $0.01 \%$ ) were applied. No eye patch was used. For the first 2 weeks after surgery, the following treatments were prescribed: TobraDex ${ }^{\circledR}$ suspension (1 mg dexamethasone and $3 \mathrm{mg}$ tobramycin per milliliter, $0.01 \%$ benzalkonium chloride) t.i.d. and TobraDex ${ }^{\circledR}$ ointment in the evening or Maxitrol ${ }^{\circledR}$ suspension (polymyxin B sulfate, 6,000 units, neomycin sulfate, 3,500 units, dexamethasone $1.0 \mathrm{mg}$, and benzalkonium chloride $0.004 \%$ ) t.i.d. and Maxitrol ${ }^{\circledR}$ ointment in the evening. Figure 2 shows postoperative photographs at $24 \mathrm{~h}$ of a 16 -year-old patient necessitating medial rectus posterior fixation surgery because of convergence excess. The eye could be opened very well and there was only minimal discomfort. In the primary position, the cuts were covered by the lids and the perilimbal conjunctiva showed only minimal redness (fig. 2a). On right gaze, the keyhole openings become visible (fig. 2 b, black arrows).

\section{Statistical Methods}

All parameter comparisons were performed between the preoperative state and the postoperative state at 6 months. Binocular vision was compared using the Wilcoxon signed-rank test. logMAR visual acuities and squint angles were analyzed with the paired $t$ test. Confidence intervals correspond to the $95 \%$ confidence level. 


\section{Results}

The patients' mean age at the time of surgery was 14.9 \pm 17.2 years (range from 3 to 62 years). Thirteen patients (25 eyes) needed posterior medial rectus muscle fixation surgery because of a convergence excess. One patient had an incomitance with diplopia on downgaze because of a right orbital floor fracture and another, on left gaze due to a previous large recession of the right medial rectus. Both patients were operated on with a contralateral posterior fixation of the agonist rectus muscle (inferior rectus and lateral rectus muscle, respectively). Four patients (5 eyes) with heavy eye syndrome were treated with a posterior fixation of the lateral rectus muscle to reduce ipsilateral hypotropia. In 23 eyes, rectus muscles were operated on with a posterior fixation suture alone. In 9 eyes, the cuts were slightly prolonged more anteriorly in order to be able, at the same time, to perform a MISS recession (between 3 and $5 \mathrm{~mm}$ ) or MISS plication (between 3 and $8 \mathrm{~mm}$ ). The posterior fixation sutures were placed at the following distances from the muscle insertion: medial rectus 13 or $13.5 \mathrm{~mm}$, lateral rectus $15-18.5 \mathrm{~mm}$, and inferior rectus $14 \mathrm{~mm}$. All 19 patients (100\%) could be followed for 6 months (range 5-7 months).

No intraoperative complication occurred. On the first postoperative day, in primary position surgery, redness was hardly visible in 16 eyes (50\%), only a moderate redness was visible in 6 eyes (19\%), a stronger redness as well as swelling were present in 4 eyes (12.5\%). In 6 eyes (19\%), the conjunctiva was chemotic and in 1 of these patients additional oral antibiotics were administered because of retrobulbar pain. Eyes with additional rectus muscle displacement displayed more redness and swelling (67 vs. 25\%). In all patients, redness and swelling resolved nearly completely within 2 weeks. No dellen or other corneal complications were observed (0/32, 95\% CI 0-8.7\%). On follow-up, 1 eye developed a granuloma around 1 conjunctival suture, which resolved after removal under slit lamp guidance using topical anesthesia.

Preoparative $\log$ MAR visual acuity, spherical and astigmatic refractive errors did not change significantly at 6 months ( $\mathrm{p}>0.1$ ). Preoperative $\log$ MAR visual acuity was $0.18 \pm 0.33$ and at 6 months $0.18 \pm 0.39$. The sphere changed in 2 eyes by $0.25 \mathrm{dpt}$. The astigmatism increased by $0.5 \mathrm{dpt}$ in 1 eye and in 2 eyes by $0.75 \mathrm{dpt}$. Changes of refraction were only observed in eyes with additional rectus muscle displacement. The preoperative convergence excess $(n=13)$ decreased from $10.3 \pm 4.1$ to $5.2 \pm 4.0^{\circ}$ $(\mathrm{p}<0.005)$ at 6 months. In all patients operated on for gaze incomitance $(n=6)$, improvement of either the field of binocular single vision, or in cases with no binocular functions, of the vertical deviation was achieved at 6 months. The average vertical deviation in primary position decreased from 5.7 to $2.2^{\circ}(\mathrm{n}=4, \mathrm{p}>0.1)$. Binocular vision remained mostly unchanged; it improved in 3 patients and decreased in 1 patient $(\mathrm{p}>0.1)$.

Six months after surgery, only minimal scarring was observed in the area of the small openings and the conjunctiva could be moved over the sclera. There were no extrusion of nonresorbable sutures (0/32, 95\% CI 0-8.7\%). One patient $(5.3 \%, 95 \% \mathrm{CI} 0-22 \%)$ was reoperated on within the first 6 months because of insufficient alignment.

\section{Discussion}

The development of keyhole surgical techniques enabled new approaches to reduce anatomical disruption in many surgical disciplines including ophthalmology. Further improvements may be expected in the future through instrument miniaturization, endoillumination, and better optical devices. In this study, a novel, less invasive rectus muscle posterior fixation technique has been described. Posterior fixation surgery is performed through two L-shaped keyhole openings far away from the limbus (fig. 1c-i). Postoperatively, such openings remain covered by the eyelids except during extreme gaze positions. This minimizes the visibility of the surgical procedure and reduces the perilimbal swelling during the immediate postoperative period (fig. 2). If the surgeon needs better visualization of the operative site, the small cuts can be enlarged or even joined with a limbal cut in order to obtain the usual opening used for posterior fixation sutures (fig. 1a, b). This was not required in this patient series. Nevertheless, excessive bleeding, which cannot be stopped through the small cuts or extensive scarring from previous surgery might require enlargement of the small cuts. The surgical procedure can be performed with the same instruments as those used for the standard limbal approach without the need for an assistant. Despite the restricted access, the MISS technique enabled adequate muscle exposure and performance of posterior fixation sutures minimizing anatomical disruption. Although not objectively measured, patient discomfort was minimal postoperatively. Eye patching or additional lubrification of the operated eyes was not necessary. At 6 months, only minimal cicatrization was found along the cuts, which allowed the conjunctiva to move freely over the sclera and muscle. This minimal scarring may facilitate future reoperations. 
A conjunctival opening located far away from the cornea should also reduce the incidence of corneal dellen formation and avoid prolapse of Tenon's capsule. However, only larger patient series will tell us whether this also applies to the new MISS technique since such complications occur only rarely. There are also indications that nonlimbal strabismus surgery has less effects on perilimbal blood supply and may safeguard anterior segment ischemia in high-risk patients [20]. Therefore, MISS techniques may be preferable in this type of patients.

Which are the limitations of this study? Although the results seem to be promising, additional studies including larger numbers of patients are necessary to confirm them since rare MISS complications might have been missed. Furthermore, the number of patients with incomitance in secondary gaze positions was small, and, therefore the effectiveness of this method also needs to be proven for this group of patients.

In summary, the technique and the results of a new MISS access technique for rectus muscle retroequatorial scleromuscular fixation were presented; the technique seems to be safe and more rational than previous procedures. Placement of the conjunctival cuts in the regions which need to be visualized to perform posterior fixation allows us to minimize the total opening size and anatomical disruption.

\section{Acknowledgements}

I would like to thank the orthoptists Andrea Kunz and Elisabeth Türk for data collection.

\section{References}

1 Darzi A, Mackay S: Recent advances in minimal access surgery. BMJ 2002;324:31-34.

2 Harrell AG, Heniford BT: Minimally invasive abdominal surgery: lux et veritas past, present, and future. Am J Surg 2005;190: 239-243.

3 Frueh BR, Musch DC, McDonald HM: Efficacy and efficiency of a small-incision, minimal dissection procedure versus a traditional approach for correcting aponeurotic ptosis. Ophthalmology 2004;111:2158-2163.

4 Luchtenberg M, Bartel JH, Bink A, KuhliHattenbach C, Berkefeld J: Clinical effectiveness of balloon dacryocystoplasty in circumscribed obstructions of the nasolacrimal duct. Ophthalmologica 2007;221:434-438.

5 Kim M, Chung SH, Lee JH, Lee HK, Seo KY: Comparison of mini-flap technique and conjunctival autograft transplantation without mitomycin $\mathrm{C}$ in primary and recurrent pterygium. Ophthalmologica 2008;222:265271.

6 Agapitos PJ: Cataract surgical techniques. Curr Opin Ophthalmol 1991;2:16-27.

$\checkmark 7$ Cillino S, Di Pace F, Casuccio A, Cillino G, Lodato G: Deep sclerectomy versus trabeculectomy with low-dosage mitomycin C: fouryear follow-up. Ophthalmologica 2008;222: 81-87.
-8 Lakhanpal RR, Humayun MS, de Juan E Jr Lim JI, Chong LP, Chang TS, Javaheri M, Fujii GY, Barnes AC, Alexandrou TJ: Outcomes of 140 consecutive cases of 25 -gauge transconjunctival surgery for posterior segment disease. Ophthalmology 2005;112:817-824.

9 Harms H: Über Muskelvorlagerung. Klin Monatsbl Augenheilk 1949;115:319-324.

10 von Noorden GK: The limbal approach to surgery of the rectus muscles. Arch Ophthalmol 1968;80:94-97.

11 Parks MP: Fornix incision for horizontal rectus muscle surgery Am J Ophthalmol 1968;65:907-915.

12 Swan KC, Talbot T: Recession under Tenon's capsule. Am Arch Ophthalmol 1954;51:3241.

13 Velez G: Radial incision for surgery of the horizontal rectus muscles. J Pediatr Ophthalmol Strabismus 1980;17:106-107.

14 Santiago AP, Isenberg SJ, Neumann D, Spierer A: The paralimbal approach with deferred conjunctival closure for adjustable strabismus surgery. Ophthalmic Surg Lasers 1998; 29:151-156.
15 Mojon DS: Comparison of a new, minimally invasive strabismus surgery technique with the usual limbal approach for rectus muscle recession and plication. Br J Ophthalmol 2007;91:76-82.

16 Mojon DS: Minimally invasive strabismus surgery for horizontal rectus muscle reoperations. Br J Ophthalmol 2008;92:16481652 .

17 Mojon DS: Minimally invasive strabismus surgery (MISS) for inferior obliquus recession. Graefe's Archive for Clinical and Experimental Ophthalmology, published online 29 October 2008.

18 Foster RS: Vertical muscle transposition augmented with lateral fixation. J AAPOS 1997;1:20-30.

19 Pfenninger L, Landau K, Bergamin O: Comparison of Harms tangent screen and search coil recordings in patients with trochlear nerve palsy. Vision Res 2006;46:1404-1410.

20 Kushner BJ: Comparison of a new, minimally invasive strabismus surgery technique with the usual limbal approach for rectus muscle recession and plication. $\mathrm{Br} \mathrm{J}$ Ophthalmol 2007;91:5. 